\title{
Effect of Human Umbilical Cord Derived Mononuclear Cells Transplantation on Ovarian Dysfunction Caused by Methotrexate in Female Rats
}

\author{
Reham E. Masoud' and Amira S. Mohammed ${ }^{2}$
}

Departments of ${ }^{1}$ Clinical Pharmacology, Faculty of Medicine, Port Said University and ${ }^{2}$ Clinical Pharmacology, Faculty of Medicine, Suez Canal University, Egypt

\begin{abstract}
Background: A search for methods to prevent infertility in patients receiving chemotherapy including methotrexate is important. Cell therapies with human embryonic and specific adult stem cells have emerged as an alternative management for various diseases. Aim: to study the effect of human umbilical cord derived mononuclear cells transplantation on ovarian dysfunction caused by methotrexate in female rats. Methods: the effect of mono nuclear cells (MNCs) treatment (IV injection once in the tail vein for diabetic rats in a dose of $150 \times 10^{6} \mathrm{MNCs}$ cells/rat) on ovary and uterus pathology, malondialdehyde (MDA) level in ovary and follicle stimulating hormone (FSH) level was assessed after methotrexate treatment. Results: Treatment with MNCs in rats pretreated with methotrexate significantly improved all parameters measured (body weight, ratio between ovary and body weight, ratio between uterus and body weight), level of MDA in ovary tissue, FSH and histopathology of ovary and uterus as compared to methotrexate only treated rats. Conclusion: These data indicate that MNCs treatment improved ovarian dysfunction associated with methotrexate therapy.
\end{abstract}

Keywords: FSH follicle stimulating hormone, MDA malondialdehyde, chemotherapy, reproductive organs.

\section{Introduction}

Long-term use of chemotherapeutic agents during the treatment of cancer in childhood and the reproductive period can lead to various complications, such as ovarian insufficiency and infertility ${ }^{(1)}$. A search for methods to prevent infertility in patients receiving chemotherapy is becoming increasingly important ${ }^{(2)}$. Methotrexate (MTX) is a folic acid antagonist and chemotherapeutic agent frequently used in hematological malignancies, such as lymphoblastic leukemia, seen in childhood and adulthood(3). Due to its immunosuppressive and antimetabolite effects, it is also effective in autoimmune diseases, such as rheumatoid arthritis and psoriasis(4). MTX exerts its effects by reversible inhibition of the enzyme dihydrofolate reductase $^{(5)}$, resulting in decreasing folate synthesis, impairing DNA synthesis, and cell multiplication. Toxicity is therefore more pronounced in cells with a rapid turnover(5). MTX has previously been shown to cause ovarian dysfunction, particularly in high doses ${ }^{(6)}$. MTX is associated with a decrease in ovarian primordial cells, although the mechanism and long-term effects have not been established $(7)$. Since primordial follicles lack the ability to regenerate, damage resulting from expo- 
sure to toxic agents can lead to ovarian insufficiency and infertility ${ }^{(8)}$. Stem cell transplantation therapy utilizing cord blood stem cells is a new therapeutic approach that has been successful in the treatment of many diseases( ${ }^{(9-10)}$. Human cord blood mono nuclear cells (HCMNCs) can be used as a source of stem cells for transplantation as they contain a large number of mesenchymal stem cells, endothelial progenitor cells and immature stem/progenitor cells ${ }^{(11-12)}$. In this study we evaluated the protective effect of human umbilical cord blood mononuclear cells transplantation against ovarian insufficiency caused by methotrexate.

\section{Materials and Methods}

Experimental animals: Twenty-eight $(\mathrm{n}=28)$ female adult albino rats weighing $170 \pm 10$ $\mathrm{g}$ were used in this study. They were purchased from the Egyptian Organization for Biological Products and Vaccines (Egypt), and allowed free access to food and water ad libitum. They were kept under constant conditions with 12/12 h light/dark cycles and left for acclimatization for one week before the start of the study. The care and handling of the animals were in accordance with the Animal Care and Use Committee at the Suez Canal University and the National Institutes of Health guide for the care and use of laboratory animals (Maryland, USA). All efforts were made to minimize animal suffering and to reduce the number of animals used.

Drugs and Chemicals: All drugs and chemicals were purchased from Sigma Aldrich, USA.

Study groups: The study included 21 rats divided into 3 groups. Each group consisted of 7 rats; Group 1: The normal healthy control group. Group2: Methotrxatetreated group injected i.p. with MTX at a dose of $2 \mathrm{mg} / \mathrm{kg}^{(13)}$. Group3 Normal group treated by Human umbilical cord blood mononuclear cells: $150 \times 100^{6}$ cells/rat once via tail vein. Group4 Methotrexate treated group received mononuclear cells 48 hour after methotrexate injection. After fourweeks, all rats were sacrificed.

MNCs isolation according to Jaatinen and Laine ${ }^{(14)}$ : HUCB samples were obtained from placentas of healthy full-term neonates. Each cord blood sample was collected into a $50 \mathrm{ml}$ sterile polypropylene test tube containing $5 \mathrm{ml}$ of citrate phosphate dextrose as an anticoagulant. The volume collected varied from 20 to $40 \mathrm{ml}$, and the samples were kept at room temperature until they were sent to the blood bank for storage. The samples were then transferred into a polyolefin blood collection bag that allows gaseous transfer and were stored at $4^{\circ} \mathrm{C}$ in a blood bank refrigerator. Donor specimens were combined according to their blood type ( $A B O)$. After storage for 10-13 days, units were placed in a $15-\mathrm{ml}$ disposable centrifuge tube and the mononuclear cells were separated from the whole cord blood by FicollHypaque density gradient centrifugation. The cells were then washed twice with phosphate buffered saline (PBS) and centrifuged for $10 \mathrm{~min}$ at $1000 \mathrm{rpm}$. One milliliter of PBS was added to the pellet for counting. After the viability and counting were determined, the mononuclear cells were centrifuged for $10 \mathrm{~min}$ at $1000 \mathrm{rpm}$, and then $0.2 \mathrm{ml}$ of PBS solution was added for final dilution and injection into the rat via tail vein.

Measurements done at the end of the study: Body weight and ratio between ovary weight to body weight were assessed at the end of the study

Biochemical analysis of ovarian tissue for MDA level: Extracted ovarian tissues of weight $0.2 \mathrm{~g}$ were homogenized in, $1 \% \mathrm{KCl}$ solution for MDA assay malondialdehyde (MDA) and made up to $2 \mathrm{ml}$. They were subsequently centrifuged at for $15 \mathrm{~min}$ at 
$+4^{\circ} \mathrm{C}$. The supernatant part was used as a specimen for analysis. All measurements of tissue-protein estimation were performed according to Bradford's method(15). Malondialdehyde (MDA) assay was based on spectrophotometric measurements at an emission wave length of 532 $\mathrm{nm}$ of the absorbance of the pink complex formed at high temperature $\left(95^{\circ} \mathrm{C}\right)$ by thiobarbituric acid and MDA ${ }^{(16)}$.

Levels of FSH: Blood samples were collected after sacrifice. The samples were incubated overnight at $4^{\circ} \mathrm{C}$, then were centrifuged for $10 \mathrm{~min}$ at $3000 \mathrm{rpm}$. The resulting supernatant sera were collected and stored at $-80^{\circ} \mathrm{C}$. Levels of FSH was measured by ELISA.

Histopathology: Tissue samples from ovary and uterus were collected and preserved in $10 \%$ neutral buffer formalin for further histopathological examination with $\mathrm{H} \& \mathrm{E}$ stain

\section{Statistical analysis}

Results were collected and expressed as the mean \pm SD. Results were analyzed using The Statistical Package for the Social Sciences, version 18 (SPSS Software). Oneway analysis of variance (ANOVA) follow- ed by Duncan's post-hoc test was used to test the significance of the difference between quantitative variables; $p$ value $<0.001$ was considered to be statistically significant.

Conflict of interest: There is no conflict of interest or funding agencies in this work

\section{Results}

\section{Measurements:}

This part of the study showed that rats treated with methotrexate had significantly lower body weight, lower ovary/body weight ratio and lower uterus /body weight ratio than other study groups (figures 1-3). Oxidative stress test in ovarian tissue: MDA level was significantly higher in methotrexate group than other groups. In methotrexate and mononuclear cells treated group MDA level was higher than normal group but was significantly lower than methotrexate group.

Histopathology: Pathology results indicated that methotrexate affects ovary function. The normal rat ovaries and mononuclear cells treated ovary exhibited an intact

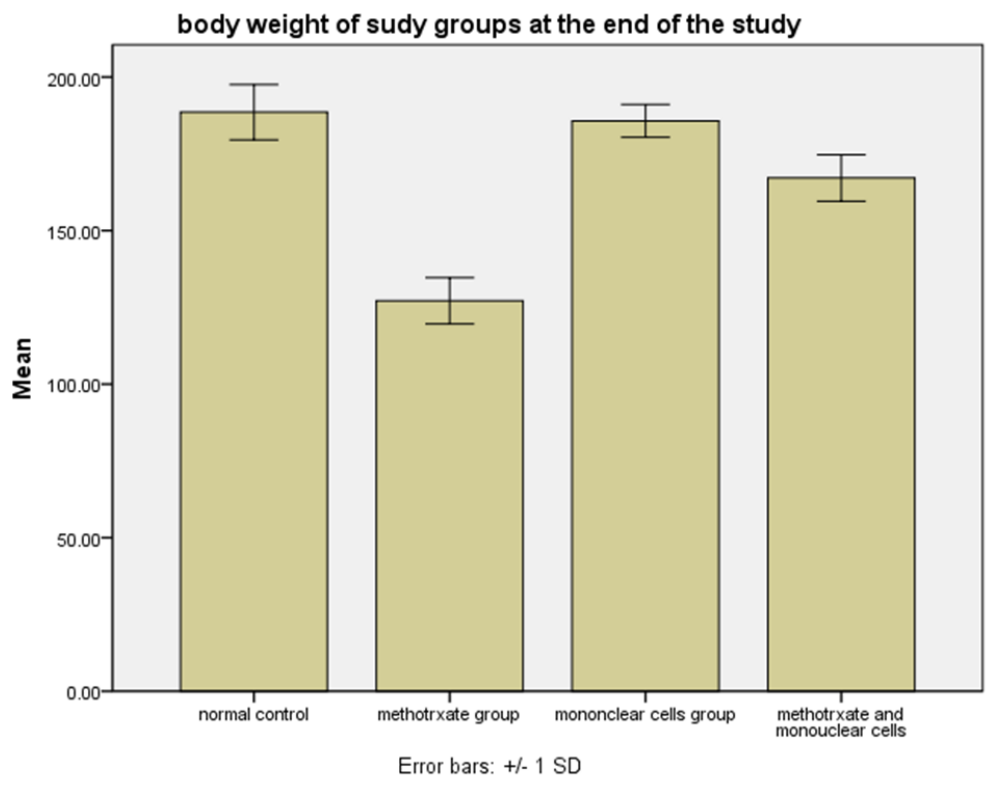

Figure 1: Body weight of different study groups at the end of the study Methotrexate group has significantly lower body weight than other study group analyzed by oneway ANOVA followed by Duncan's multiple comparisons test, $\mathrm{p}<0.05$ 
structure, and the ovarian interstitial cells were appropriately loose for ovulation. In the methotrexate-treated rats, however, the numbers of atretic follicles and primary follicles were increased, and the rat ovarian granuloma cells become more closely distributed and inflammatory cell infiltration into the ovaries was observed. in methotrexate and mononuclear cells treated rats, there was a decrease in inflammatory cells infiltration and appearance of ovarian follicles as shown in fig. 6 . FSH level: There was significantly higher level of FSH in methotrexate group than other study groups as shown in fig.5. The uterus of normal rats showed normal ar- chitecture and normal columnar epithelium lining and uterine glands. Control uterus showed lumen surrounded by numerous mucosal folds of endometrium lined by tall, tightly packed columnar epithelium. The stroma was dense. MTX treatment decreased the epithelial height, a decrease in secretory and ciliated cells were notably exhibited. in methotrexate treated rats there was sloughing off and atrophy of the lining endometrial epithelial cells, damage to endometrial glands. methotrexate and mononuclear cells treated rats showed normal histopathology as shown in fig7

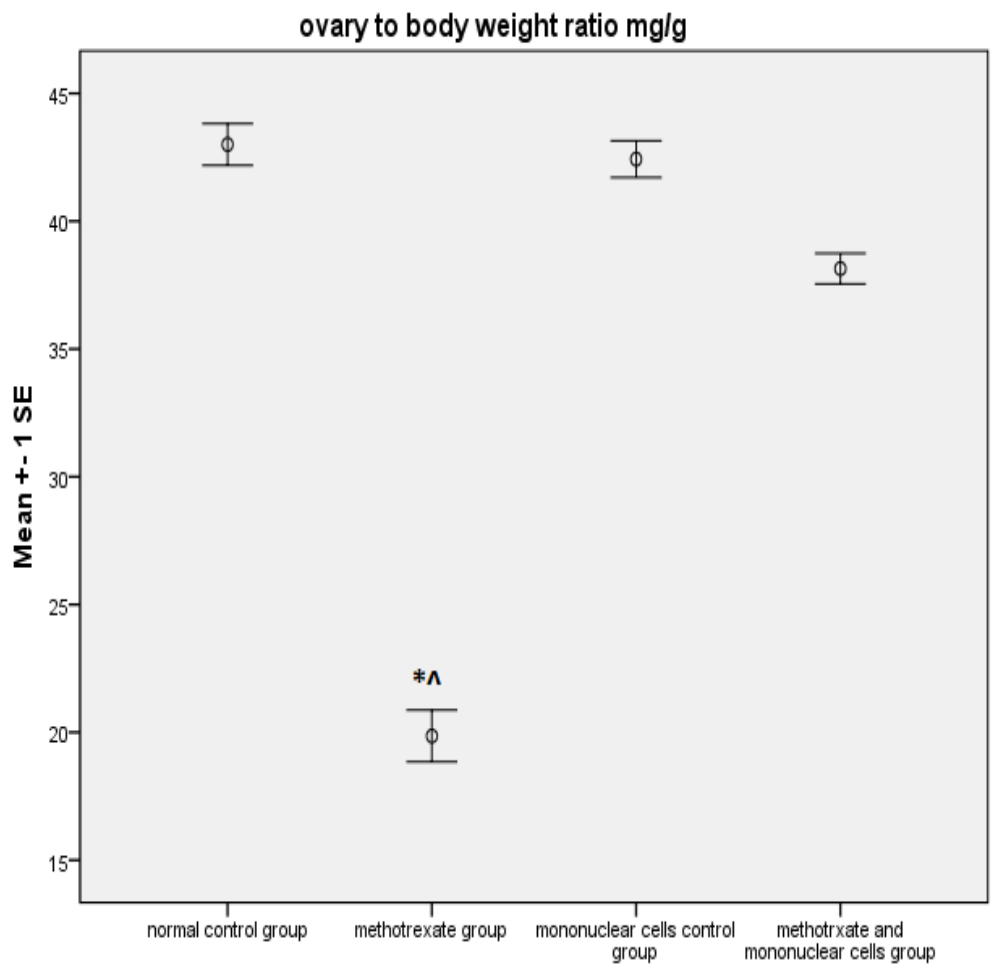

Figure 2: Ovary/ body weight ratio $(\mathrm{mg} / \mathrm{g})$ in study groups expressed as the mean $\pm S D(n=7)$, analyzed by one-way ANOVA followed by Duncan's multiple comparisons test. *, ^ $\mathrm{p}<0.001 ;$ * compared with normal control group, ^ compared with methotrexate and mononuclear cells treated group.

\section{Discussion}

This study investigated whether human umbilical cord mononuclear cells is effective in preventing ovarian damage in rats with ovarian damage induced with methotrexate, and it showed that mechanism of organ toxicity of MTX seems to be oxidative stress. Methotrexate has been re- ported to increase MDA and MPO levels, the known oxidant parameters, and to reduce the levels of GPO, an antioxidant parameter ${ }^{(17)}$. As our results show, there was a rise in MDA level in ovarian tissue in rats receiving methotrexate. These findings indicate that the oxidant/antioxidant balance in ovarian tissue in rats receiving MTX changes in favor of oxidants. Various 
aggressive factors that may lead to tissue damage can result in the oxidant/ antioxidant balance being impaired in favor of oxidants and cause oxidative stress ${ }^{(18)}$. Data from reference sources and our results show that MTX also causes oxidative stress in ovarian tissue. The fact that MDA concentrations were higher in the MTX group ovarian tissue than in other groups reflects the severity of lipid peroxidation in the cell membrane. Lipid peroxidation is a reaction where free oxygen radicals of polyunsaturated fatty acids generate products such as peroxides and MDA. The MDA produced causes irreversible more severe damage in the cell(19).

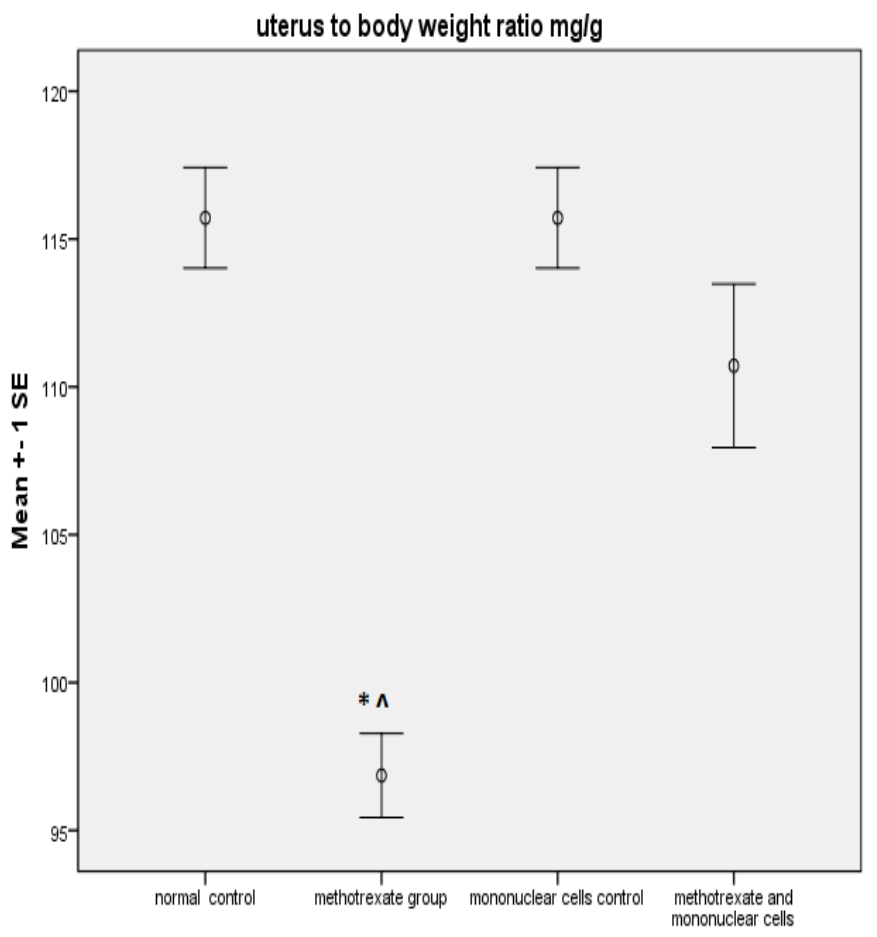

Figure 3: uterus/ body weight ratio ( $\mathrm{mg} / \mathrm{g}$ ) in study groups expressed as the mean $\pm S D(n=7)$, analyzed by one-way ANOVA followed by Duncan's multiple comparisons test.

*,^ $\mathrm{p}<0.001$; * compared with normal control group, $\wedge$ compared with methotrexate and mononuclear cells treated group.
Wang et al. found that HUMSCs transplantation reduced chemotherapeutic-induced apoptosis of mouse ovarian cells and restored ovarian estrogen secretion ${ }^{(20)}$. These results suggested that this technique could treat ovary injury because of chemotherapy. In other studies ${ }^{(21-23)}$, mesenchymal stem cells were derived from adipose seed cells and amniotic fluid to treat ovarian injury because of chemotherapy. More recently the use of umbilical cord stem cells for xenotransplantation has been considered. Rats treated with methotrexate alone showed lower body weight, ovary to body weight ratio and uterus to body weight ratio. The possible reason may be that the reduction in folate content and alteration of folate co- enzyme pattern may alter cell differentiation and tissue growth. Factors affecting both protein synthesis and degradation determine cytoplasmic growth ${ }^{(24)}$. There was significantly elevated level of FSH in methotrexate only treated group which may suggest ovarian dysfunction and unresponsiveness to this hormone in this group as compared to mononuclear cells treated group ${ }^{(21)}$.

\section{Conclusion}

The use of human umbilical cord blood mononuclear transplantation prevented reproductive organs damage and reduced ovarian oxidative stress in rats treated with methotrexate. 




Figure 4: MDA level in study groups ( $\mu \mathrm{mol} / \mathrm{g}$ protein), values are expressed as the mean \pm SD $(n=7)$, analyzed by oneway ANOVA followed by Duncan's multiple comparisons test.

*,\#, \$,^ $\mathrm{p}<0.001 ;$ * compared with normal control group, \# compared with mononuclear cells group, \$ compared with methotrexate and mononuclear cells treated group and ${ }^{\wedge}$



Figure 5: Level of FSH $\mathrm{mIU} / \mathrm{ml}$ in study groups expressed as the mean $\pm S D(n=7)$, analyzed by one-way ANOVA followed by Duncan's multiple comparisons test.

*,^ $\mathrm{p}<0.001 ;$ * compared with normal control group, $\wedge$ compared with methotrexate and mononuclear cells treated group.

\section{References}

1. Sonmezer M, Oktay K. Fertility preservation in female patients. Hum Reprod Update 2004;10 (3), 251-66.

2. Oktay K, Buyuk E, Libertella N, Akar M,
Rosenwaksv. Fertility preservation in breast cancer patients: a prospective controlled comparison of ovarian stimulation with tamoxifen and letrozole for embryo cryopreservation. J Clin Oncol 2005;23 (19), 4347-53. 


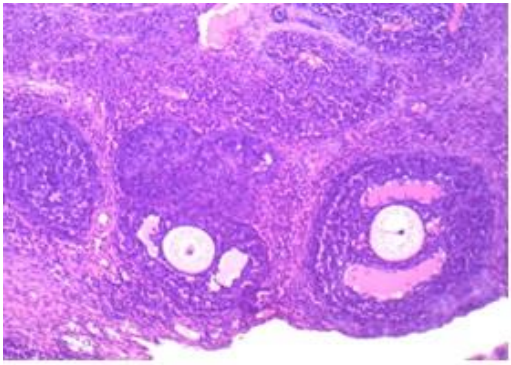

A

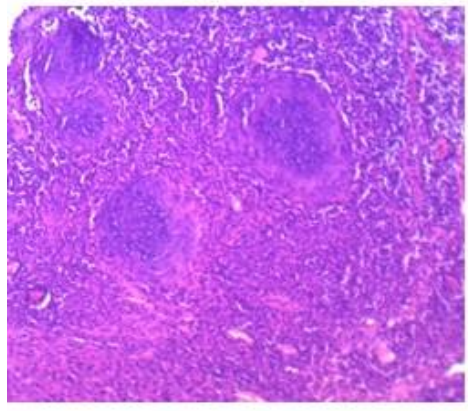

C



A

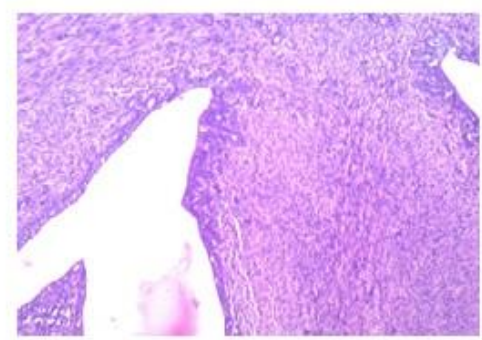

C

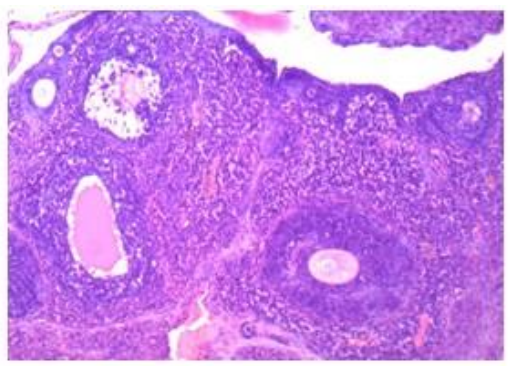

B
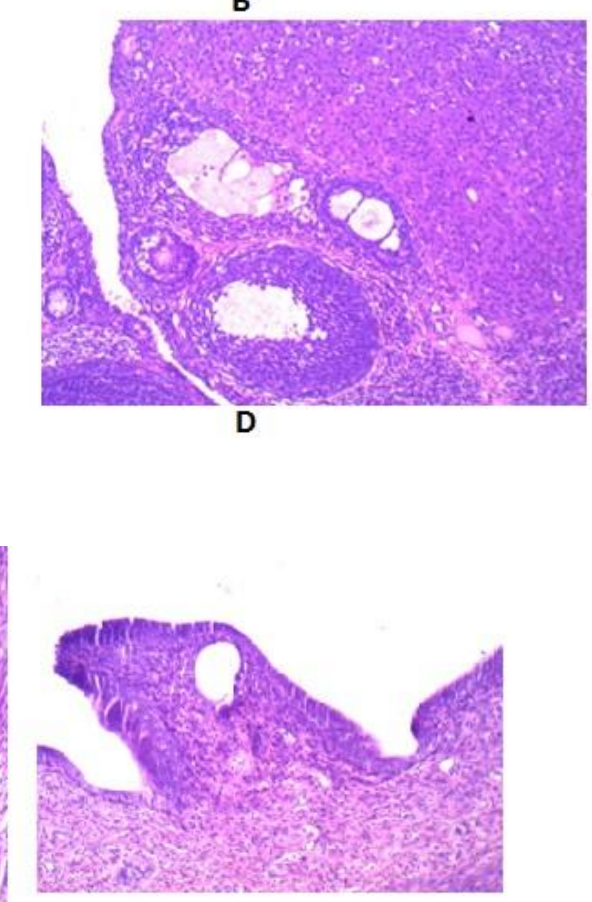

B

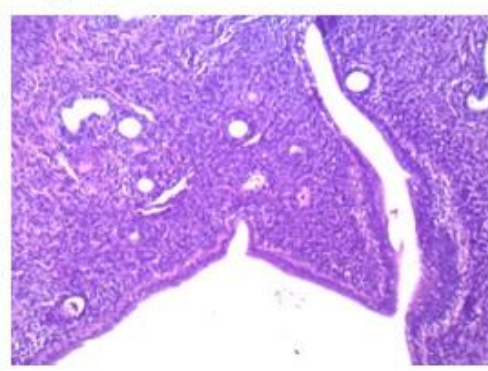

Figure.7: Hisolpathology of uterus in study groups A: -normal control, B: -mononuclear cells treated, C: methotrxate treated, D: -methotrexate and mononuclear cells treated group
3. de Deus DMV, de Lima ELS, Seabra Silva RM, Leitev EP, Cartaxo Muniz MT. Influence of methylene tetrahydrofolate reductase $\mathrm{C} 677 \mathrm{~T}, \mathrm{~A} 1298 \mathrm{C}$, and G80A polymorphisms on the survival of pediatric patients with acute lymphoblastic leukemia. Leuk Res Treat 2012, Article ID 292043,

4. Prasad R, Koul V. Transdermal delivery of methotrexate: Past, present and prospects. Ther Deliv 2012;3(3), 31525.

5. Stika CS. Methotrexate: The pharmacology behind medical treatment for ectopic pregnancy. Clin Obstet Gynecol 2012; 55(2): 433-9.

6. Shamberger RC, Sherins RJ, Ziegler JL, Glatstein E, Rosenberg SA. Effects of postoperative adjuvant chemotherapy and radiotherapy on ovarian function in women undergoing treatment for 
soft tissue sarcoma. J Natl Canc Inst 1981;67(6): 1213-8.

7. Gol M, Saygili U, Koyuncuoglu M, Uslu $\mathrm{T}$. Influence of high-dose methotrexate therapy on the primordial follicles of the mouse ovary. J Obstet Gynaecol Res 2009;35(3): 429-33.

8. Yucebilgin MS, Terek MC, Ozsaran A, et al. Effect of chemotherapy on primordial follicular reserve of rat: An animal model of premature ovarian failure and infertility. Aust N Z J Obstet Gynaecol. 2004; 44(1): 6-9.

9. Prasad VK, Kurtzberg J. Emerging trends in transplantation of inherited metabolic diseases. Bone Marrow Transplant 2008; 41(2): 99-108.

10. Barker JN, Weisdorf DJ, DeFor TE, et al. Transplantation of 2 partially HLAmatched umbilical cord blood units to enhance engraftment in adults with hematologic malignancy. Blood 2005; 105(3): 1343-7.

11. Hirata $Y$, Sata $M$, Motomura $N$, et al. Human umbilical cord blood cells improve cardiac func-tion after myocardial infarction. Biochem Biophys Res Commun 2005; 327(2): 609-14

12. Erices A, Conget $P$, Minguell JJ. Mesenchymal progenitor cells in human umbilical cord blood. $\mathrm{Br} J$ Haematol 2000; 109(1): 235-42

13. Yapcaa OE, Borekcib B, Turanc M, Gulapoglud $M$, Salmane $S$. The effect of mirtazapine on methotrexate-induced oxidative damage and infertility in rats. Science Asia 40 (2014): 152-156

14. Jaatinen T, Laine J. Isolation of Mononuclear Cells from Human Cord Blood by Ficoll-Paque Density Gradient. Curr Protoc Stem Cell Biol. 2007; Chapter 2: Unit 2A.1, 8-11.

15. Bradford MM. A rapid and sensitive method for the quantitation of microgram quantities of protein utilizing the principle of protein-dye binding. Anal Biochem. 1976; 72, 248-54.
16. Ohkawa H, Ohishi N, Yagi K. Assay for lipid peroxides in animal tissues by thiobarbituric acid reaction. Anal Biochem. 1979; 95(2), 351-8.

17. Demiryilmaz I, Sener E, Cetin N, et al. Biochemically and histopathologically comparative review of thiamine's and thiamine pyrophosphate's oxidative stress effects generated with methotrexate in rat liver. Med Sci Monit 2012;18(12): BR475-81.

18. Kisaoglu A, Borekci B, Yapca OE, Bilen $\mathrm{H}$, Suleyman $\mathrm{H}$. Tissue damage and oxidant/antioxidant balance. Eurasian J Med. 2013 ;45(1):47-9.

19. Wang S, Yu L, Sun M, et al. The therapeutic potential of umbilical cord mesenchymal stem cells in mice premature ovarian failure. Biomed Res Int. 2013; 2013:690491.

20. Cighetti G, Duca L, Bortone L, et al. Oxidative status and malondialdehyde in beta-thalassaemia patients. Eur J Clin Invest. 2002; 32(Suppl 1), 55-60.

21. Takehara $Y$, Yabuuchi A, Ezoe K, et al. The restorative effects of adiposederived mesenchymal stem cells on damaged ovarian function. Lab Invest. 2013; 93(2):181-93.

22. Liu T, Huang Y, Guo L, Cheng W, Zou G. CD44+/CD105+ human amniotic fluid mesenchymal stem cells survive and proliferate in the ovary long-term in a mouse model of chemotherapyinduced premature ovarian failure. Int J Med Sci. 2012; 9(7):592-602.

23. Sun $M$, Wang $S$, Li $Y$, et al. Adiposederived stem cells improved mouse ovary function after chemotherapyinduced ovary failure. Stem Cell Res Ther. 2013; 4(4):80.

24. Sritulasi K Gopalakrishnan CR Vanithakumari G. Antiestrogenic and anti progestational activity of methotrexate and its effect on uterine histoarchitecture of ovariectomized albino rats. bioresearch bulletin j., 2010; 1 (3). 